\title{
Role of membrane compartment occupied by Can 1 (MCC) and eisosome subdomains in plant pathogenicity of the necrotrophic fungus Alternaria brassicicola
}

\author{
Justine Colou', Guillaume Quang N'Guyen ${ }^{1,2}$, Ophélie Dubreu', Kévin Fontaine ${ }^{1,3}$, Anthony Kwasiborski', \\ Franck Bastide ${ }^{1}$, Florence Manero ${ }^{4}$, Bruno Hamon', Sophie Aligon ${ }^{1}$, Philippe Simoneau ${ }^{1}$ and Thomas Guillemette ${ }^{1 *}$ (D)
}

\begin{abstract}
Background: MCC/eisosomes are membrane microdomains that have been proposed to participate in the plasma membrane function in particular by regulating the homeostasis of lipids, promoting the recruitment of specific proteins and acting as provider of membrane reservoirs.

Results: Here we showed that several potential MCC/eisosomal protein encoding genes in the necrotrophic fungus A. brassicicola were overexpressed when germinated spores were exposed to antimicrobial defence compounds, osmotic and hydric stresses, which are major constraints encountered by the fungus during the plant colonization process. Mutants deficient for key MCC/eisosome components did not exhibit any enhanced susceptibility to phytoalexins and to applied stress conditions compared to the reference strain, except for a slight hypersensitivity of the Mabpilla-abpillb strain to $2 \mathrm{M}$ sorbitol. Depending on the considered mutants, we showed that the leaf and silique colonization processes were impaired by comparison to the wild-type, and assumed that these defects in aggressiveness were probably caused by a reduced appressorium formation rate.

Conclusions: This is the first study on the role of MCC/eisosomes in the pathogenic process of a plant pathogenic fungus. A link between these membrane domains and the fungus ability to form functional penetration structures was shown, providing new potential directions for plant disease control strategies.
\end{abstract}

Keywords: Eisosome, Fungi, Plant pathogen, Appressoria, Seed, Plasma membrane

\section{Background}

The plasma membrane (PM) acts as a protective barrier for all living cells and mediates a variety of dynamic processes, including nutrient uptake, endocytosis, exocytosis, cell wall biogenesis or signal transduction [1-3]. To achieve these processes, the PM is highly compartmentalized consisting of distinct subdomains with different protein / lipid environments and specialized functions. In yeast, several large membrane compartments have been characterized: MCC (Membrane Compartment of Can1, arginine permease), MCT (Membrane Compartment of TORC2, target of

\footnotetext{
* Correspondence: thomas.guillemette@univ-angers.fr

${ }^{1}$ Institut de Recherche en Horticulture et Semences - UMR 1345, INRA, Université d'Angers, Agrocampus-Ouest, SFR 4207 QuaSaV, 42 rue Georges Morel, 49071 Beaucouzé Cedex, Angers, France

Full list of author information is available at the end of the article
}

rapamycin kinase complex 2) and MCP (Membrane Compartment Pmal, acting as an $\mathrm{H}+$ plasma membrane ATPase) [4-7]. More recently, another distinct punctate compartment was identified and called Membrane Compartment occupied by Wsc1 (MCW), which plays an essential role for cell wall integrity pathway activation [8].

The MCC domains have been found only in fungal cells, microalgae and lichens [9]. They were associated with peripheral membrane proteins located on the cytoplasmic side forming a complex termed eisosome [10]. Together, MCCs and eisosomes form a stable and immobile PM structure associated with membrane invaginations that are about $300 \mathrm{~nm}$ long and $50 \mathrm{~nm}$ deep furrows [11]. Contrary to MCP, MCC/eisosomes probably do not have a direct role in dynamic processes such

(C) The Author(s). 2019 Open Access This article is distributed under the terms of the Creative Commons Attribution 4.0 International License (http://creativecommons.org/licenses/by/4.0/), which permits unrestricted use, distribution, and 
as endocytosis and secretion, since eisosome proteins do not colocalize with actin patches or sites of endocytosis [4-6, 12]. Membrane protein constituents of MCCs include several proton symporters, such as $\mathrm{Can} 1(\mathrm{H}+$ /arginin symporter), Fur4 (H+/uracile symporter), and Tat2 ( $\mathrm{H}+$ /tryptophan or $\mathrm{H}+$ /tyrosine symporter) $[13,14]$, as well as members of different families of tetraspan proteins that are known to have four transmembrane domains [14-16]. The first family of tetraspanners found in MCCs includes Sur7 and the paralogous proteins Fmp45, Pun1, and Ynl194c. The second family of tetraspanners contains Nce102 and Fhn1. Pil1 and its paralog Lsp1 in yeast, or their homologous Pil(1)A / Pil(1)B in filamentous fungi, are the most abundant proteins in eisosomes. These two proteins are essential for the membrane curvature and formation of furrows by assembling into filaments and binding membrane through their BAR (Bin/Amphiphysin/Rvs) domains [17, 18]. In yeast, Pil1 and Lsp1 are regulated by a pair of redundant protein kinases Pkh1 and Pkh2 mediating the longchain-base-signaling pathway. However, the impact of these phosphorylation/dephosphorylation on the MCC/ eisosome structure is still unclear [19-23].

$\mathrm{MCC} /$ eisosomes have been proposed to participate in the plasma membrane function by regulating the lipid homeostasis, in particular sphingolipids and phosphatidylinositol 4,5- bisphosphate (PI4,5P $\left.\mathrm{P}_{2}\right)[16,24,25]$. Moreover, due to their specific lipid composition, they would promote the recruitment of specific proteins and their subsequent protection from endocytosis $[14,26]$ and also would act as provider of membrane reservoirs required for membrane expansion in response to particular stresses [27, 28]. Mutations targeting $\mathrm{MCC} /$ eisosome proteins in yeasts and filamentous fungi can result in abnormal hyphal morphogenesis and promote other defects in endocytosis, autophagic processes, cell wall synthesis or protection against stresses [2, 18, 29]. Moreover, MCC/eisosomes have been found to contribute to pathogenicity of Candida albicans and Beauveria bassiana, infecting humans and arthropods, respectively [29-32]. Several factors may explain the virulence reduction in MCC/eisosome mutants. First, in $C$. albicans, sur 7 and nce102 mutants were defective in forming hyphal filaments that promote invasive growth into tissues. MCC/eisosome mutants were also generally found to be more sensitive to a variety of stresses and to host immune response encountered in vivo [33]. Finally, in $B$. bassiana, all single/double deletion mutants of pillA and pil1B resulted in reduced ability to secrete Pr1 proteases required for host cuticle degradation [29]. More recently, [34] showed that deletion of Sfp2, which is a tetraspan protein (more closely related to yeast Pun1 than to Sur7), resulted in strong defects in polarized growth, cell wall integrity and endocytosis in the mycoparasitic fungus Trichoderma atroviride. The deletion or overexpression of spf 2 also significantly altered mycoparasitic activity of $T$. atroviride as well as the transcriptional regulation of chitin synthase and chitinase-encoding genes [34].

In this study, we investigated the importance of the $\mathrm{MCC} /$ eisosomes with respect to the ability of the plant necrotrophic fungus Alternaria brassicicola to efficiently accomplish key steps of its pathogenic life cycle. A. brassicicola is an economically important seed-borne pathogen of Brassicaceae species causing black spot disease on aerial parts of the plants, including siliques, seeds and stems. Its transmission to seeds is a major component of pathogen fitness promoting the dispersal and long-term survival of the fungus [35]. Here, we first identified the major components of the $\mathrm{MCC} / \mathrm{eisosomes}$ in the A. brassicicola genome and followed their gene expression in response to various stresses encountered by the fungal pathogen during the infection process of its host. Then, we investigated the role of major $\mathrm{MCC} /$ eisosome components on pathogenicity by phenotyping deficient mutants.

\section{Results \\ Identification of a. brassicicola MCC/eisosome components}

From the interactive JGI fungal portal MycoCosm (http:// genome.jgi.doe.gov/Altbr1/Altbr1.home.html) A. brassicicola proteome, we searched for homologous proteins of the main Saccharomyces cerevisiae MCC/eisosome proteins, based on the protein set reported by [2]. We identified ten A. brassicicola eisosomal proteins and six others MCC proteins (Table 1). Two A. brassicicola proteins (AB08863 and AB09572, called AbPIL1A and AbPIL1B, respectively) are homologous to yeast Pil1 and Lsp1, and are 50.8\% identical in sequence. AbPIL1A and AbPIL1B proteins are 353 and 431 amino acids long, respectively, and both contain an arfaptin homology (AH)/ Bin-Amphiphysin-Rvs (BAR) domain, which consists of three alpha-helices. As described by $[29,36]$, each sequence harbors the typical central coiledcoil domain and low complexity regions located on each side at $\mathrm{N}$-terminus and C-terminus (Fig. 1). Phylogenic analysis showed that AbPIL1A was distinct from yeast Pil1/ Lsp1 homologues and was grouped with Pil1A proteins from B. bassiana and aspergilli (Fig. 1). As expected, AbPIL1B sequence fell into the Pil1B clade. Concerning membrane proteins that are constituents of MCCs, only one homologous protein to yeast Sur7 and Nce102, respectively, was found in the A. brassicicola genome. While three putative members of the Sur7 family of proteins were present in Aspergillus nidulans, AbSUR7, the only representative from A. brassicicola, showed strong identity (42\%) to the A. nidulans SurG protein (ANID_04615.1), considered to be the Sur7 orthologue of S. cerevisiae and C. albicans [36]. The AbNCE102 protein also shared strong identity with Nce102 homologues in S. cerevisiae (37\% with YPR149W) and A. nidulans (42\% with ANID_07683). 
Table 1 Homologous proteins in A. brassicicola of the main S. cerevisiae MCC/eisosome proteins and their gene expression in response to applied treatments. Brassinin, camalexin, sorbitol and desiccation treatments were compared to non-treated cultures at two time points $(0.5 \mathrm{~h}$ and $2 \mathrm{~h}$, or $1 \mathrm{~h}$ and $4 \mathrm{~h}$ ). Genes with a $P$-values $\leq 0.01$ and a log 2 ratio $\geq 0.5$ or $\leq-0.5$ were considered as differentially expressed. Values corresponds to log2 ratio

\begin{tabular}{|c|c|c|c|c|c|c|c|c|c|c|c|c|c|}
\hline \multirow[b]{2}{*}{ Eisosome } & \multirow[t]{2}{*}{ Protein } & \multirow[t]{2}{*}{$\begin{array}{l}\text { A. brassicicola } \\
\text { ID }\end{array}$} & \multirow{2}{*}{$\begin{array}{l}\text { S. cerevisiae } \\
\text { homolog } \\
\text { (\% identity) }\end{array}$} & \multirow[t]{2}{*}{ Function } & \multirow[t]{2}{*}{ Reference } & \multicolumn{2}{|c|}{$\begin{array}{l}\text { Exposure } \\
\text { to brassinin }\end{array}$} & \multicolumn{2}{|c|}{$\begin{array}{l}\text { Exposure } \\
\text { to camalexin }\end{array}$} & \multicolumn{2}{|c|}{$\begin{array}{l}\text { Exposure } \\
\text { to sorbitol }\end{array}$} & \multicolumn{2}{|c|}{$\begin{array}{l}\text { Exposure to } \\
\text { dehydration }\end{array}$} \\
\hline & & & & & & $\begin{array}{l}0.5 \\
\mathrm{~h}\end{array}$ & $2 \mathrm{~h}$ & $0.5 \mathrm{~h}$ & $2 \mathrm{~h}$ & $\begin{array}{l}0.5 \\
\mathrm{~h}\end{array}$ & $2 \mathrm{~h}$ & $1 \mathrm{~h}$ & $4 \mathrm{~h}$ \\
\hline & Pil1A & AB08863.1 & YGR086C (73\%) & BAR domain & [10] & 0.88 & & 0.62 & & 2.27 & 0.88 & 1.38 & 1.59 \\
\hline & Pil1B & AB09572.1 & YPL004C (50\%) & BAR domain & [10] & & & & & & & & \\
\hline & SIm1 & AB02000.1 & YIL105C (37\%) & $\begin{array}{l}\text { BAR domain and } \\
\text { PH domain }\end{array}$ & {$[38]$} & 2.01 & 0.9 & 1.6 & & 1.55 & & 2.48 & 1.74 \\
\hline & $\operatorname{SIm} 2$ & AB05189.1 & YNL047C (24\%) & $\begin{array}{l}\text { BAR domain and } \\
\text { PH domain }\end{array}$ & [38] & & & & & & & 1.18 & 0.61 \\
\hline & Pkh1 & AB04691.1 & YDR490C (50\%) & Ser/Thr protein kinase & {$[14,20]$} & & & & & & & & \\
\hline & Pkh2 & AB07167.1 & YGR092W (55\%) & Ser/Thr protein kinase & {$[14,20]$} & & & & & & & & \\
\hline & Pst2 & AB10448.1 & YCR004C (51\%) & flavodoxin-like proteins & {$[36]$} & & & & & & & & \\
\hline & Mdg1 & AB06956.1 & YHR146W (38\%) & Unknown & {$[36]$} & 0.85 & & & & & & & \\
\hline & Ycp4 & AB02777.1 & $\begin{array}{l}\text { YCR004C / YDR032C } \\
(57 \%)\end{array}$ & flavodoxin-like proteins & {$[36]$} & & & & & & 0.79 & & \\
\hline & Xrn1 & AB10419.1 & YGL173C (63\%) & Exonuclease & [37] & & & & & & & & \\
\hline \multirow[t]{6}{*}{ MCC } & Sur7 & AB08885.1 & YML052W (34\%) & Sur7 family tetraspan & {$[4,6]$} & 1.5 & & 0.98 & & 1.72 & & 1.91 & 1.81 \\
\hline & Pun1 & AB03912.1 & YLR414C (26\%) & Sur7 family tetraspan & [36] & & & & & 1.39 & 0.94 & & \\
\hline & Nce102 & AB04716.1 & YPR149W (37\%) & $\begin{array}{l}\text { Nce102 family } \\
\text { tetraspan }\end{array}$ & [36] & 1.59 & & 1.05 & & 1.61 & & 1.61 & 1.66 \\
\hline & Can1 & AB08516.1 & YEL063C (43\%) & $\begin{array}{l}\mathrm{H}^{+} \text {-driven } \mathrm{Arg} \\
\text { permease }\end{array}$ & [6] & & -0.96 & & & -0.8 & -0.61 & $\overline{0}-96$ & \\
\hline & Fur4 & AB04392.1 & YIR028W (46\%) & $\begin{array}{l}\mathrm{H}^{+} \text {-driven uracil } \\
\text { permease }\end{array}$ & {$[5]$} & & & & & & & & -1.06 \\
\hline & Tat2 & AB08109.1 & YKR039W (52\%) & $\begin{array}{l}\mathrm{H}^{+} \text {-driven Trp and } \\
\text { Tyr permease }\end{array}$ & [14] & & & & & & & & \\
\hline
\end{tabular}

AbSUR7 and AbNCE102 have a typical structure based on four transmembrane domains. AbNCE102 also harbors a Marvel (MAL and related proteins for vesicle trafficking and membrane link) domain, consistent with function related to cholesterol-rich membrane apposition events in a variety of cellular processes. Interestingly we did not find obvious $A$. brassicicola homologues for the following yeast proteins: Fmp45 and Ynl194c (Sur7 family tetraspan), Fhn1 (Nce102 family tetraspan), Rfs1 (flavodoxin-like proteins), Eis1, Seg1, Ygr130c, and Msc3 (all are eisosomal proteins with unknown function).

\section{Expression patterns of a. brassicicola MCC/eisosome components}

During leaf and silique infection, $A$. brassicicola, as a necrotrophic agent, is exposed to high levels of antimicrobial defence compounds, such as the indolic phytoalexins brassinin and camalexin. During colonization of maturing seeds, the fungus is exposed to severe water and osmotic constraints $[37,38]$. Its ability to cope with such stresses is probably a key factor that determines its aggressiveness and the efficiency of the seed transmission process. To assess if MCC/ eisosome may be involved in response to these stresses, we analyzed the $\mathrm{MCC} /$ eisosome gene expression in germinated spores of A. brassicicola exposed to either indolic phytoalexins brassinin and camalexin (this study) or to water stress (data obtained from [39]). Thus, we produced transcriptome datasets using $A$. brassicicola microarrays bearing one probe for each of the 10,633 ORFs predicted in the $A$. brassicicola automatically annotated genome database. The numbers of genes that were induced or repressed under brassinin or camalexin treatments are shown in the Additional file 2: Figure S1. Global modulation of gene expression in A. brassicicola in response to sorbitol and desiccation treatments was previously reported [39].

After exposing germinating conidia to water stresses or indolic phytoalexins, the expression patterns of AbPIL1, AbSLM1, AbSUR7 and AbNCE102 were found to be similar, the corresponding genes being up-regulated at least for one exposure time of each treatment (Table 1). Expression 

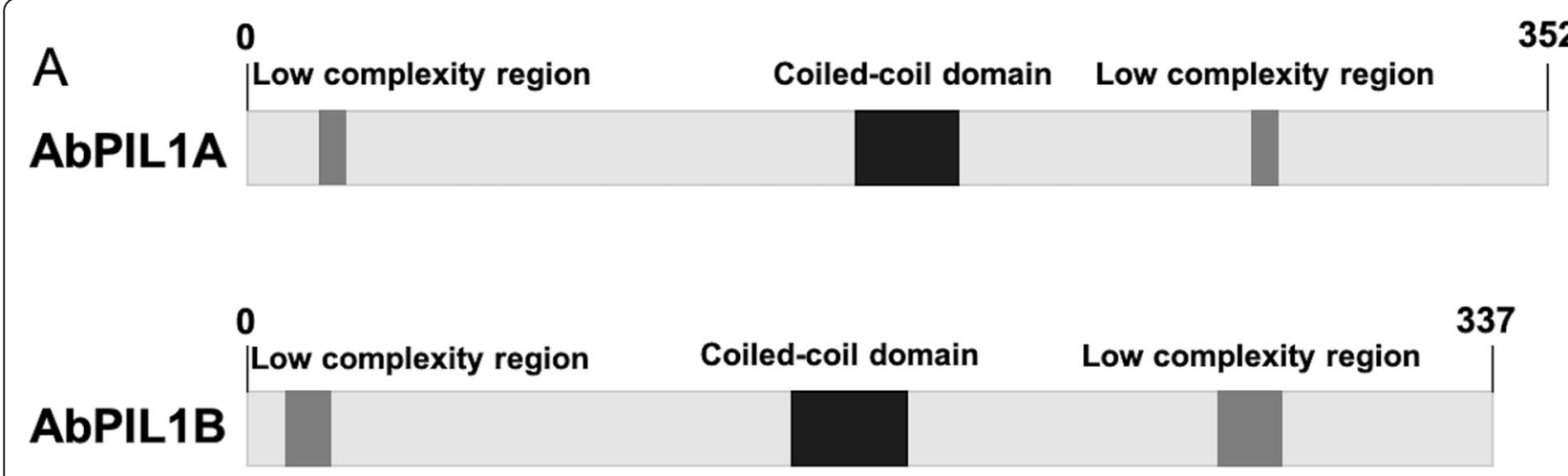

B

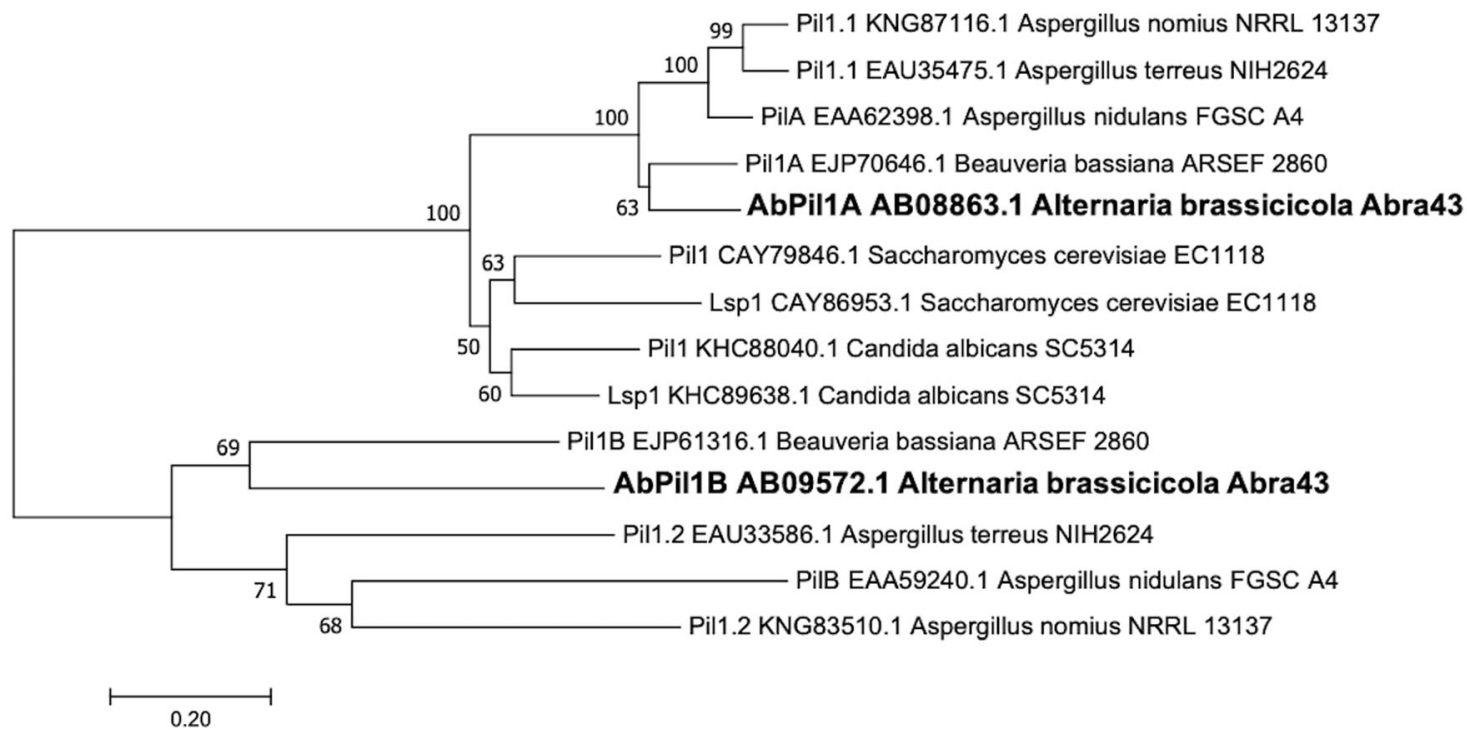

Fig. 1 Bioinformatic features of PIL1A and PIL1B homologues in A. brassicicola. a Conserved domains predicted from the respective sequences of AbPIL1A and AbPIL1B using SMART software at http://smart.emblheidelberg.de/. b Phylogenetic tree for AbPIL1 and LSP1 homologs found in B. bassiana (Bba), Aspergillus species (Ate: A. terreus; Ano: A. nomius; and Ani: A. nidulans and yeasts (Cal: Candida albicans; Cor: C. orthopsilosis; and Sce: S. cerevisiae). The phylogenetic analysis was based on the neighbor-joining method in MEGA7 software at http://www.megasoftware.net/. Bootstrap values of 1000 replications are given at nodes

of some genes were induced by only one treatment. For instance, $A b P u n 1$ and $A b Y c p 4$ were induced by the exposure to sorbitol. In contrast, some genes were not differentially regulated (such as the eisosomal protein kinases AbPkh1 and $A b P k h 2$ ), or were repressed (AbCan1 and AbFur4) by some treatments. Surprisingly, the $A b P i l 1 B$ gene, that is considered as a potential paralog of $A b P i l 1 A$, did not show any change in expression.

\section{Subcellular localization of a. brassicicola MCC/eisosome proteins}

Strains expressing MCC/eisosome proteins (AbPIL1A, AbSUR7 or AbNCE102, respectively) from their respective endogenous promoter and fused at their carboxy-terminal end to sGFP were engineered. These transformed strains did not show any visible phenotypic changes compared to the wild-type except for expression of green fluorescence (data not shown). As expected, visualization in laser scanning confocal microscopy of hyphal cells showed that AbPIL1A fusion protein tagged by sGFP formed many regular punctuate spots in the PM. These patches were found to be static during a 90-min period of monitoring in the presence or not of DMSO (Fig. 2). In young hyphae, AbNCE102-GFP and AbSUR7-GFP also formed patches in the PM and additionally in intracellular structures. During a 90-min period of growth in the presence of DMSO, this internal staining strongly diminished in the AbNCE102GFP strain while the peripheric staining remained stable (Fig. 2). The intracellular localizations of these three proteins were consistent with those visualized for the MCC/ 


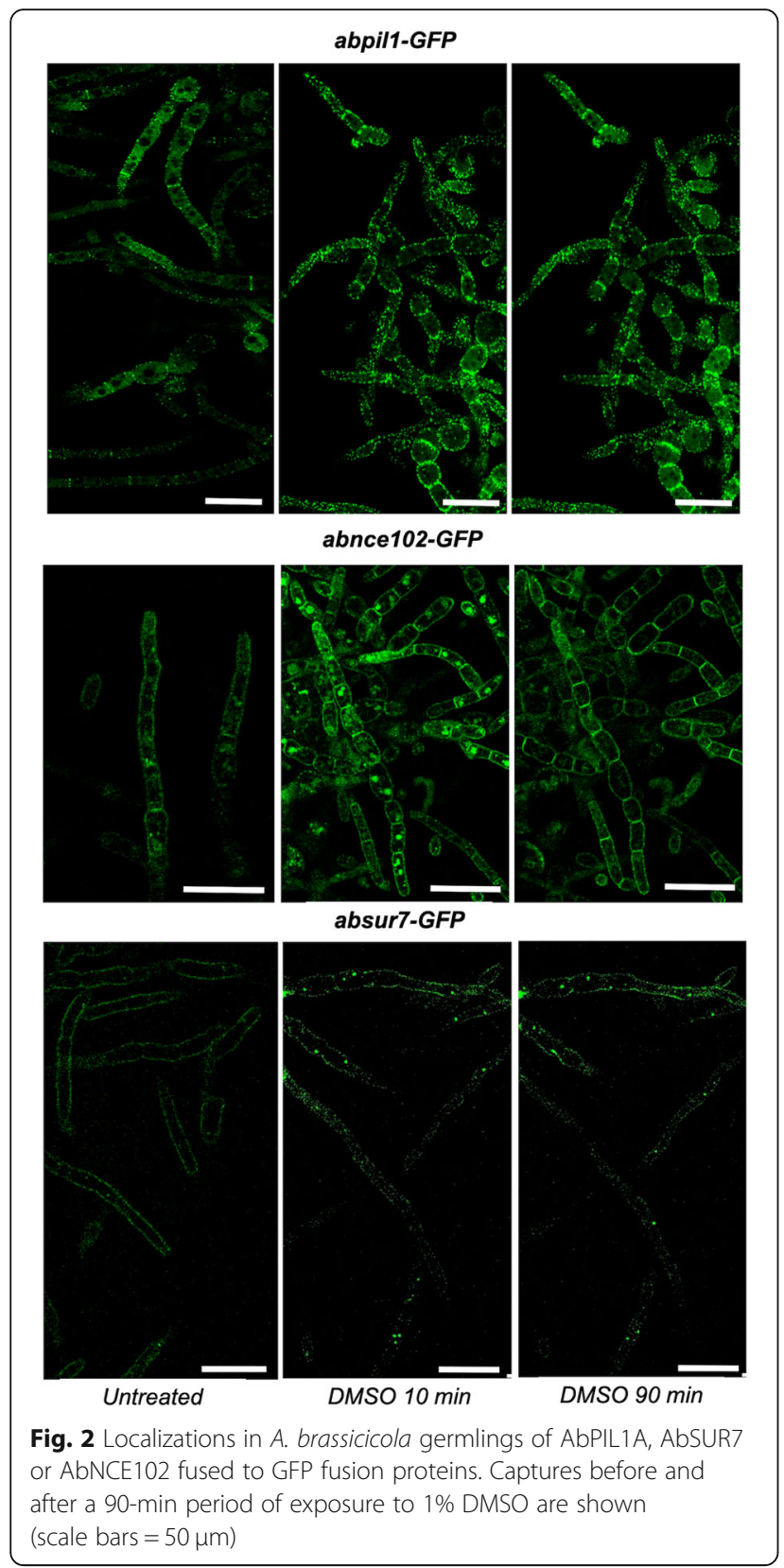

eisosome proteins in other fungi, such as A. nidulans: all showed a PM staining pattern, and NCE102 and SUR7 were additionally detected in other internal structures [39; 42].

Response of MCC/eisosome mutants to stress conditions Knockout mutants deficient for AbPIL1A, AbPIL1B, AbSLM1, AbNCE102 (called $\triangle a b p i l 1 a, \Delta a b p i l 1 b, \Delta a b s l m 1$, and $\Delta a b n c e 102)$, respectively, were generated. $\Delta \Delta a b p i l 1 a-$ abpil1b double deletion mutants were also constructed. Despite several attempts, we have failed to generate viable AbSur7 mutants, suggesting that the deletion of this gene in A. brassicicola is lethal.
Monitoring growth in standard solid / liquid medium (PDA or PDB) did not reveal any significant effect of $\mathrm{MCC} /$ eisosome mutations, compared to the parental strains, on the mycelium growth rate, conidia germination and initial hyphal growth (Additional file 3: Figure S2). We then compared the susceptibility of MCC/eisosome mutants and the wild-type strain to various stress conditions, indicated in Table 2. In general, mutants showed only a few significant differences compared to wild-type. For instance, we did not notice any significant susceptibility to indolic phytoalexins and cell wall stress under these particular growth conditions compared to the wild-type. The most notable difference is the slight hypersensitivity of the $\Delta \Delta a b p i l 1 a$-abpil1b strain to $2 \mathrm{M}$ sorbitol and to DMSO.

\section{Investigation of the conidial ultrastructure}

We investigated the morphology of the wild-type and mutant quiescent conidia using transmission electron microscopy (TEM). As shown in the Fig. 3 for the WT and $\Delta a b p i l 1 b$ strains, the young spores were small, slightly elongated and without cross-section. Older spores usually had two cross-sections or more (as shown for the Aabpilla strain in the Fig. 3). However, we observed that the cell wall of the double mutant $\Delta \Delta a b p i l 1 a$-abpil1b formed extensive invaginations. Young spores of the double mutant had indeed one or more septa that were transverse and sometimes longitudinal (Fig. 3). This type of structure was not observed neither in the wild strain nor in the single mutants.

Moreover, the aspect of autophagosomes was examined more specifically since it has already been reported by [29] in $B$. bassiana that deletions of eisosomal genes could impair the formation of intravacuolar autophagosomes. In $A$. brassicicola, the aspect of autophagosomes was also found to be altered in several mutants. The Abpil1A mutant did not seem to form autophagosomes or only formed small altered ones in vacuoles. In contrast, in the $\Delta a b p i l 1 b$ cells, vacuolar lumens were filled with hyper-developed autophagosomes, which appeared even larger than in wild-type vacuoles (Fig. 3). No specific alteration of autophagosomes was noted in $\Delta a b s l m 1$ and $\Delta a b n c e 102$ cells compared to wild-type cells (data not shown).

\section{Impact of MCC/eisosome proteins on a. brassicicola virulence}

Virulence of the wild-type and deficient mutants was compared on Brassica oleracea host plants by inoculation experiments on leaves (Fig. 4). All these genotypes were able to produce symptoms, i.e. necrotic areas surrounded by chlorotic halos at six days post-infection (dpi). However, smaller necrotic lesions with very limited spread around the inoculation sites were observed on tissues inoculated with the $\Delta a b p i l 1 a, \Delta a b p i l 1 b, \Delta \Delta a b p i l 1 a$-abpil1b 
Table 2 Susceptibility of A. brassicicola wild-type and MCC/eisosome mutant strains to different stress conditions

\begin{tabular}{|c|c|c|c|c|c|c|}
\hline Applied stress & WT & sabpil1a & sabpil1b & Mabpilla-abpil1b & Sabnce102 & $\Delta a b s / m 1$ \\
\hline 2 M Sorbitol & $39.7 \pm 1.9$ & $40.8 \pm 2.3$ & $44.9 \pm 2$ & $51.5 \pm 2.2 *$ & $40.3 \pm 1.4$ & $45.3 \pm 2.9$ \\
\hline $100 \mu \mathrm{M}$ Brassinine & $40.4 \pm 3$ & $39.8 \pm 8$ & $38.7 \pm 1.6$ & $36.7 \pm 1.9$ & $31.1 \pm 4.6$ & $33.3 \pm 1.5$ \\
\hline $60 \mu \mathrm{M}$ Camalexin & $66.3 \pm 2.8$ & $58.1 \pm 1.3$ & $64.9 \pm 3.9$ & $61.8 \pm 6.4$ & $53.9 \pm 1.5$ & $62 \pm 1.8$ \\
\hline DMSO (1\%) & $16.5 \pm 1.8$ & $19.7 \pm 1.36 *$ & $13.9 \pm 4.2$ & $27.4 \pm 5.2 *$ & $22.1 \pm 1.9 *$ & $10.2 \pm 5.1$ \\
\hline 30 mM Menadione & $61.6 \pm 3.6$ & $61.1 \pm 7$ & $62.6 \pm 6.8$ & $59.5 \pm 2.8$ & $56.3 \pm 10$ & $60.7 \pm 2.8$ \\
\hline $400 \mathrm{mg}^{\mathrm{L} \mathrm{L}^{-1} \text { Calcofluor White }}$ & $55.3 \pm 0.9$ & $52.9 \pm 1.5$ & $53.4 \pm 1.7$ & $57 \pm 4.1$ & $50.3 \pm 1.7$ & $55.3 \pm 1.8$ \\
\hline $100 \mathrm{mg} . \mathrm{L}^{-1}$ Congo Red & $45.7 \pm 1.6$ & $42.1 \pm 0.9$ & $40.8 \pm 5.2$ & $44.9 \pm 1.7$ & $40.4 \pm 1.1$ & $39.9 \pm 4.7$ \\
\hline
\end{tabular}

The results are expressed as the percentage of inhibition in treated samples compared to the control without additive. Conidia of each genotype were used to inoculate microplate wells containing standard PDB medium supplemented with the appropriate compound. Nephelometric growth was automatically recorded for $33 \mathrm{~h}$ at $24^{\circ} \mathrm{C}$. Each condition was tested in triplicate and the experiments were repeated three times. The areas under the curves were used to calculate the percentages of inhibition for each treatment compared to the control growth curves. Values are means and standard errors of at least nine biological repetitions and represent the percentage growth inhibition under stress conditions compared with standard growth conditions. Conditions denoted with * $(p \leq 0.05)$ were significantly different compared with their respective control

and $\triangle a b n c e 102$ mutants, compared to the lesion sizes obtained from the wild-type or $\Delta a b \operatorname{lm} 1$ strains (Fig. 4).

One day after inoculation, leaves were collected and observed using environmental scanning electron microscopy (SEM). Following spore attachment, we observed that conidia of all deficient mutants germinated with the same efficiency than wild-type conidia on epidermal surface. The emerging germ tubes of fungal necrotrophs often end with appressoria, which are specialised infection structures used to gain entry to plant internal tissues [40]. The germ tube hooks and forms a typical swollen tips from which an infection peg grows and enters the host using turgor pressure and/or enzymatic action. As shown in Fig. 5, more than a quarter of the wild-type germ tubes differentiated swollen tips corresponding to characteristic appressoria-like structures. Moreover, a typical white halo appeared around several appressoria revealing the presence of a functional

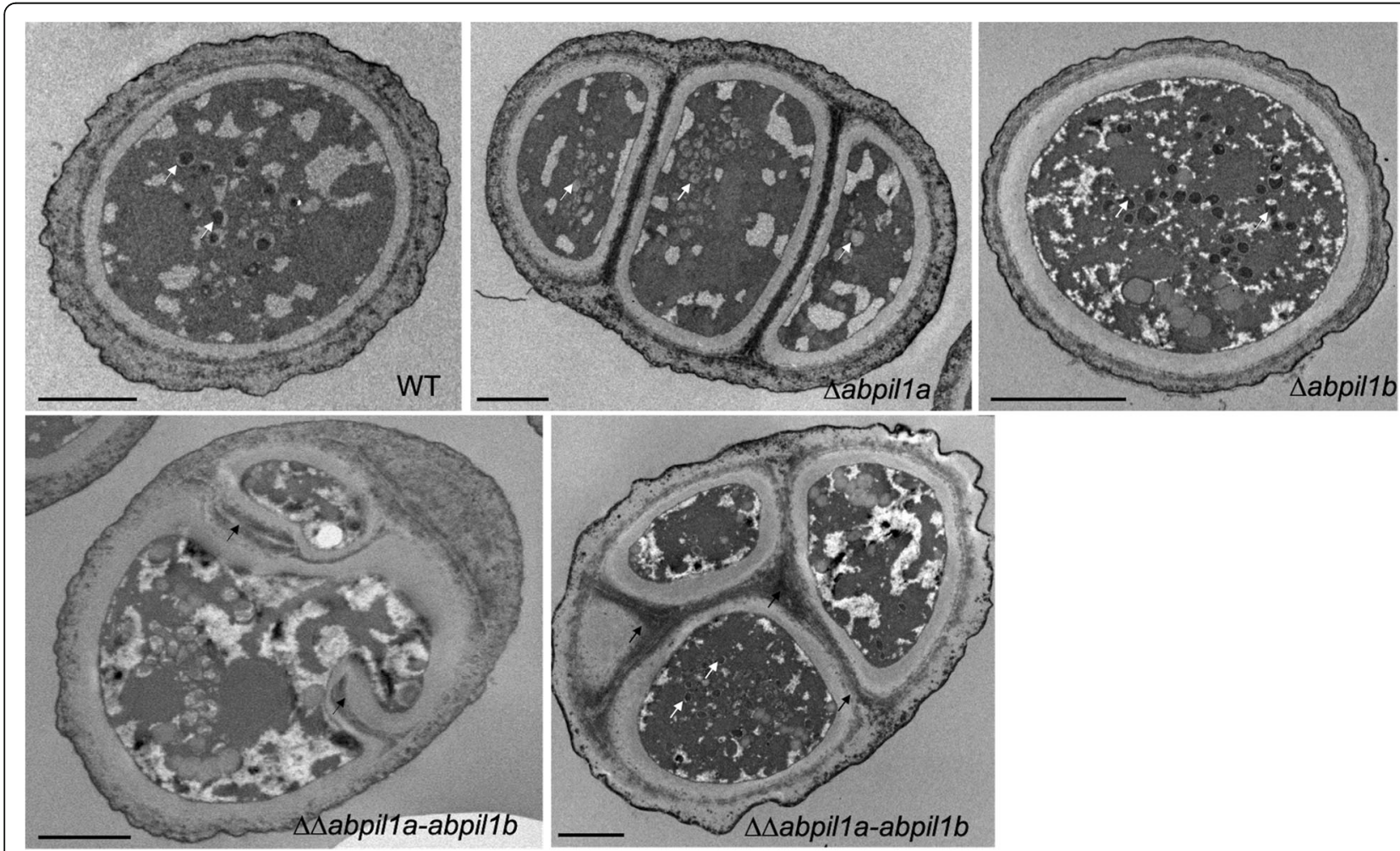

Fig. 3 Ultrastructure of A. brassicicola conidial cells. Transmission electron micrographs were performed from 7-day-old wild-type (WT) and MCC/ eisosome mutant conidia (scale bars $=2 \mu \mathrm{m}$ ). White arrows indicate autophagosomes and black arrows indicate abnormal tubular structures with cell wall material in the middle of the cell 


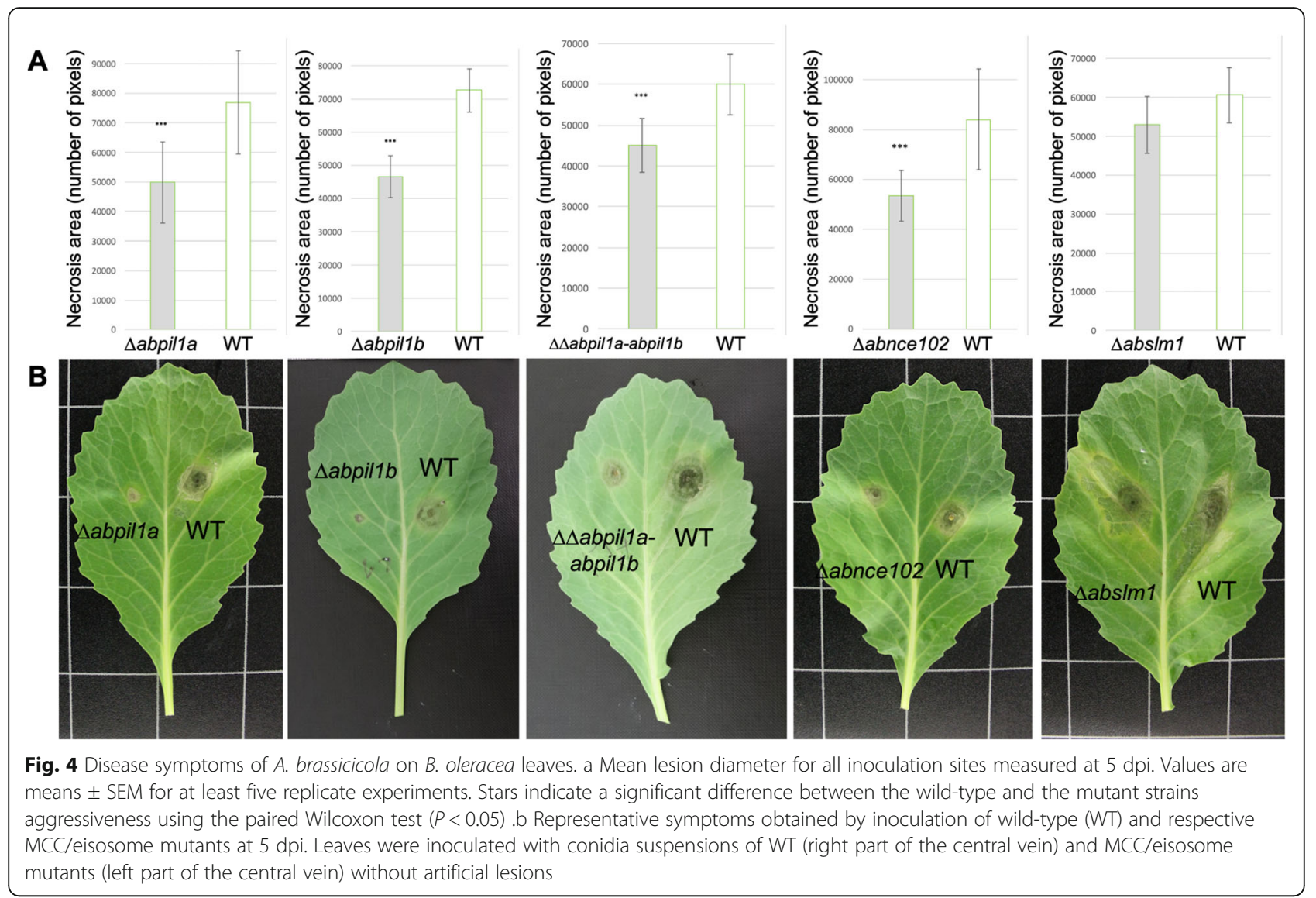

appressorium that allowed the penetration of the fungus into host tissues. Except for the $\Delta a b s \operatorname{lm} 1$ strain, the number of appressorial structures with swollen tips was found to be strongly reduced for other deficient genotypes compared to the wild-type strain, and in particular for $\Delta \Delta a b p i l 1 a$-abpillb for which only $5 \%$ of germ tubes produced swollen tips.

Using the model pathosystem previously described by [37] for investigating A. brassicicola seed transmission in Arabidopsis thaliana Ler ecotype, the ability of the MCC/ eisosome mutants to transmit to seeds was compared with that of the wild-type. Silique inoculation with the wildtype and mutant strains resulted in the onset of necrotic lesions typical of black spot on siliques within a few days after inoculation. However, a significant decrease in global seed transmission was observed for the $\Delta a b p i l 1 a$, $\triangle a b p i l 1 b, \Delta \Delta a b p i l 1 a$-abpil1b deletion mutants compared to the wild-type (Fig. 6). No significant transmission alteration was observed for $\Delta a b n c e 102$ and $\Delta a b s l m 1$ strains.

\section{Discussion}

The S. cerevisiae MCC/eisosome protein sequences were used as probes to identify homologues in the A. brassicicola genome. We identified ten $A$. brassicicola eisosomal proteins, including AbPIL1A and AbPIL1B, and six others MCC proteins, including AbSUR7 and AbNCE102.

The intracellular localizations of AbPIL1A, AbSUR7 or AbNCE102 were investigated by expressing respective GFP fusion proteins from their respective endogenous promoter. In $A$. brassicicola, the intracellular localizations of these three proteins were consistent with those visualized for the $\mathrm{MCC} /$ eisosome proteins in yeasts and other filamentous fungi. First, deconvoluted $\mathrm{Z}$ stacks of AbPIL1A and timelapse live-cell imaging in quiescent conidia and germlings showed stable punctuate spots with a plasma membrane staining pattern, as previously observed in S. cerevisiae, $C$. albicans, Ashbya gossypii, A. nidulans and B. bassiana [10, 29, 36, 41, 42]. As expected, AbSUR7-GFP localized to static patches in the PM but a punctuate intracellular fluorescence signal was also observed in hyphae. This is consistent with the localization pattern of SurG-GFP in $A$. nidulans, that was found as patches at the cell periphery of the spores and was additionally localized perinuclearly [36]. In germlings, AbNCE102 showed a PM staining pattern, consistent with a MCC/eisosome localization, and was additionally detected in other intracellular structures, that could be endoplasmic reticulum (ER) and vacuoles, as previously reported in yeast and $A$. nidulans. In $A$. nidulans, a co-localization of AnNce102 with the chaperone ShrA from 


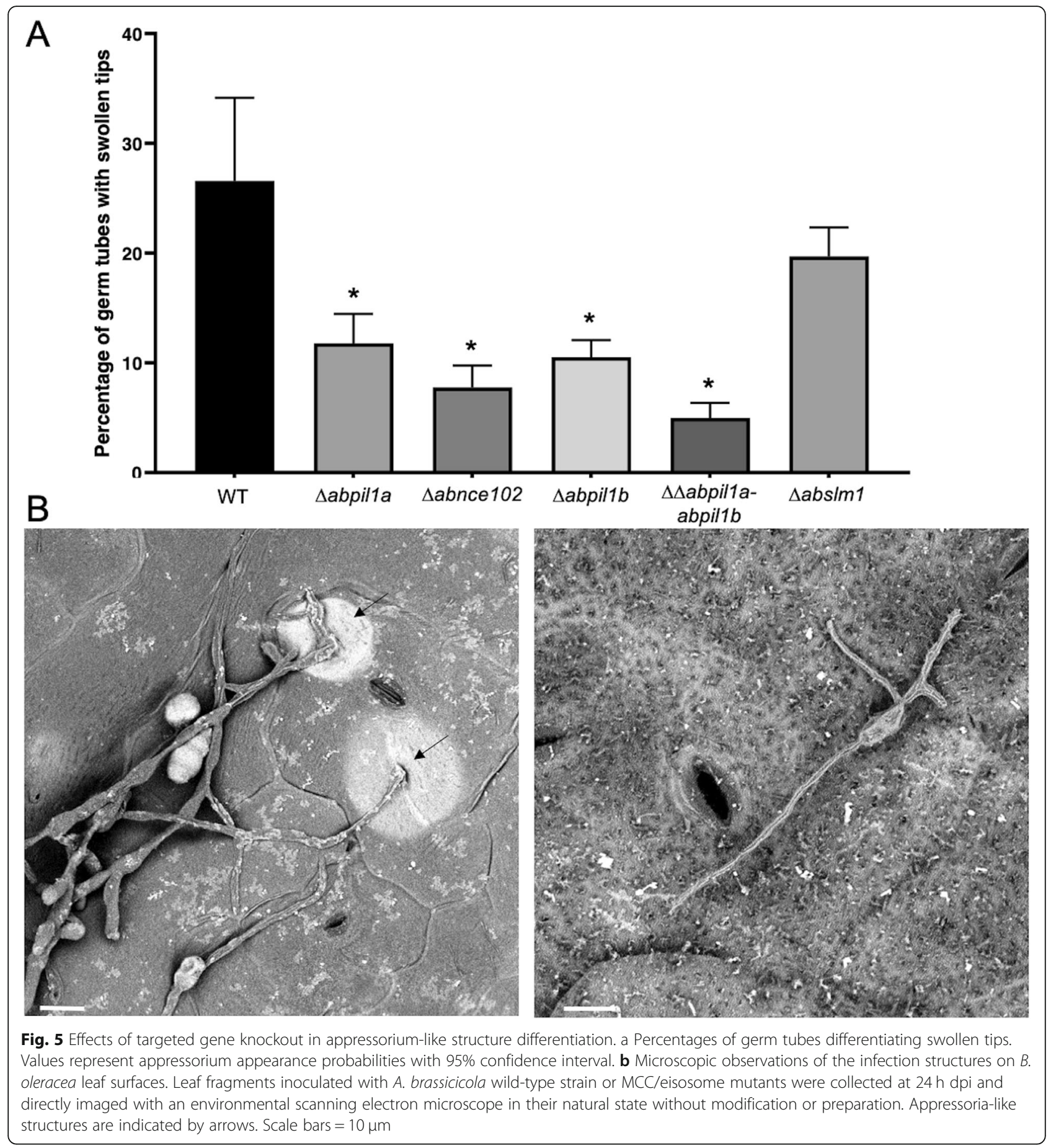

the ER and with the vacuolar tracer CMAC was reported [43]. Here, using time-lapse live-cell imaging during a 90min period of growth in the presence of DMSO, we showed that AbNCE102 formed stable spots with low mobility at the PM. On the contrary, the staining of internal organelles strongly diminished [43]. also showed that the spatial AnNce102 distribution could fluctuate during germination of $A$. nidulans. In parallel, we also generated a abpil1b-GFP strain but the resulting fluorescence signal was almost undetectable into the fungal cells and was too weak to investigate a possible co-localization of AbPIL1A with AbPIL1B, as it was reported in other fungi. This low level of fluorescence might be due to a low level of the AbPIL1B protein compared to AbPIL1A, as already suggested from our transcriptomic analysis, or to an artifactual event during the construction of the transgenic strain. 


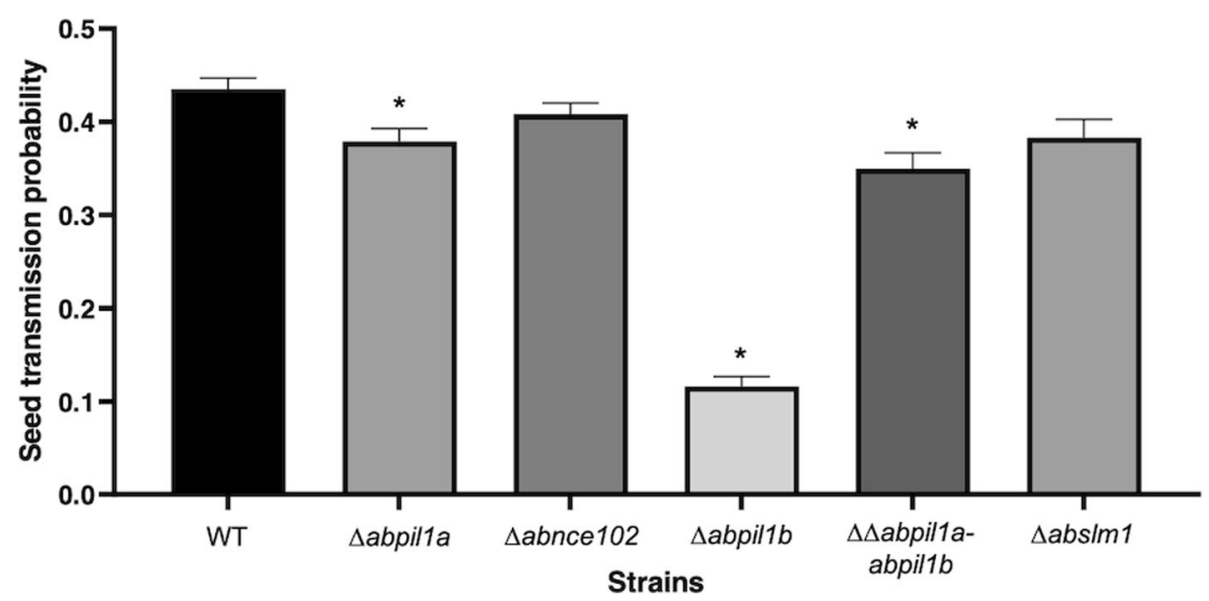

Fig. 6 Transmission capacity of A. brassicicola wild-type (WT) and MCC/eisosome mutants to Arabidopsis thaliana seeds (Ler ecotype). The seed transmission capacity according to the silique stage and global seed transmission capacity (strain model) were measured as described by [37]. The five oldest siliques of at least five plants were inoculated with each fungal genotype and the experiment was repeated. Contaminated siliques were harvested $10 \mathrm{dpi}$. After dissection, seeds were incubated separately on PDA medium for 2 days. A seed was considered contaminated when incubation resulted in typical $A$. brassicicola colony development. For each inoculated fungal genotype, the seed infection probability was evaluated from at least 1000 seeds. Values represent infection probabilities with 95\% confidence interval

Although abpil1a, abnce102 and absur7 were found to be over-expressed after exposing germinating conidia to water stresses or indolic phytoalexins, the respective deficient strains did not exhibit any significant susceptibility to various stress conditions, with the exception of a slight hypersensitivity of mutant strains to $2 \mathrm{M}$ sorbitol

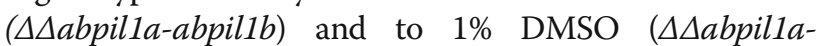
abpil1b, $\Delta a b p i l 1 a, \Delta a b n c e 102)$. Compared to wild-type, the most noticeable differences concerned the conidial ultrastucture. As reported in $\Delta \Delta$ pillisp 1 and $\Delta s u r 7$ cells of C. albicans [44] and in $\Delta$ pil1 cells of S. cerevisiae [10], $\Delta$ Aabpil1-ablsp1 cell walls formed extensive invaginations [44]. suggested that these abnormal cell wall phenotype were probably linked to abnormal regulation of PI4,5 $\mathrm{P}_{2}$, since similar broad invaginations of cell wall material were observed in a C. albicans $\Delta i n p 51$ mutant or in an S. cerevisiae $\Delta$ Ainp51-inp52 mutant, which lacks PI5-specific PI4, $5 \mathrm{P}_{2}$ phosphatases [44-46]. Consistently, they showed that sites of altered cell wall growth were associated with elevated levels of PI4,5P $\mathrm{P}_{2}$ in $\Delta \Delta$ pill-lsp1 and $\Delta s u r 7$ [44]. Interestingly, compared to wild-type, A. brassicicola MCC/ eisosome mutants did not exhibit thicker cell walls and did not show hypersensitivity to cell wall stress, as it was reported in other fungi $[29,44]$. We also examined the aspect of autophagosomes in A. brassicicola MCC/eisosome mutants and observed that $\Delta a b p i l 1 a$ and $\triangle a b p i l 1 b$ mutants failed to form normal autophagosomes. In fungi, autophagy mediates the incorporation of the cytoplasm and organelles into vacuoles or lysosomes for degradation. This process, which is negatively regulated by the phosphatidylinositol kinase-related kinase Tor in yeast [47], plays an important role (i) in maintaining cellular homeostasis by allowing the elimination and continuous replacement of non-functional proteins and organelles and (ii) in promoting adaptation and survival of cells under stress conditions [48, 49] [29]. previously observed the enlargement and abolishment of autophagosomes in B. bassiana $\triangle$ pillA and $\triangle p i l 1 B$, respectively. They also reported that deletions of pillA and pil1B caused opposite changes in expression of many autophagy-related genes and that nearly basal expression patterns were restored by application of exogenous rapamycin [29]. All these results suggested a strong link between the target of rapamycin (TOR) signaling pathway and MCC/eisosome for the completion of the autophagic process in filamentous fungi.

For the first time, the role of $\mathrm{MCC} /$ eisosomes in the pathogenic process of a plant pathogenic fungus was investigated. A. brassicicola is a necrotrophic fungus causing black spot disease in a wide range of Brassicaceae plants. Contrary to biotrophic pathogens that derive nutrients from living host tissues, A. brassicicola kills and absorbs nutrients from dead or dying cells of aerial parts of its hosts. Once the fungus has entered plant tissue, it grows subcuticularly and kills epidermal cells by secreting toxic metabolites, although no host-specific toxins have been identified so far in this fungus and that some of its pathogenesis mechanisms are still unclear [50]. In this study, we showed that, with the exception of $\triangle a b s \operatorname{lm} 1$, the MCC/ eisosomal mutants had reduced virulence on $B$. oleracea leaves. Since these mutants do not exhibit particular vulnerability to phytoalexin or oxidative stress, we hypothesize that their impaired virulence is mainly due to a very low appressorium formation rate. Appressoria are usually differentiated in response to chemical (such as epicuticular 
waxes and cutin monomers) or physical (hydrophobicity, thigmotropism) cues $[40,51]$. Unlike the model fungus Magnaporthe oryzae which accumulates glycerol as a solute within the appressorium to generate enormous cellular turgor [52], A. brassicicola, as most necrotrophs do, forms inconspicuous appressoria. It probably penetrates the plant cuticle by secreting large amounts of plant cell wall-degrading enzymes from these specialised infection structures. However, it is not clear whether the buildup of large turgor pressure also occurs in A. brassicicola appressoria. The presence of symptoms, even in mutants that produce fewer appressoria, was probably due to the ability of the fungus to alternatively penetrate through natural openings, such as stomata or wounds, as previously described by [37]. For all the MCC/eisosome mutants and wild-type strains, occasional penetrations of hyphae through stomata were indeed observed,

Based on the extensive works (in particular in M. ory$z a e$ ) aimed at identifying the cellular and molecular mechanisms involved in appressorium generation [40,53], we can put forward several hypotheses to explain the alteration of appressoria production in $\mathrm{MCC} /$ eisosome mutants. First, we can guess that the localization of actins and septins is probably altered in A. brassicicola MCC/ eisosome mutants. A first clue consistent with this hypothesis is that some $S$. cerevisiae septin mutants formed abnormal cell wall invaginations [54] as seen in A. brassicicola $\Delta$ Aabpilla-abpil1b. Septins are cytoskeletal GTPbinding proteins that were first described as involved in bud emergence in yeast by assembling into filaments and forming a ring on the inner surface of the plasma membrane [55]. Septins are also able to interact with BAR proteins (such as Pil1 and Lsp1) involved in membrane curvature generation [56]. In addition to cytokinesis, they are essential for other critical cellular processes, such as spatial compartmentalization and polar growth, and act as membrane diffusion barriers. As a consequence, septins were shown to play a major role in fungal pathogenesis, in particular by driving the invasive growth [57]. In $M$. ory$z a e$, a hetero-oligomeric septin ring forms at the base of the appressorium and scaffolds F-actin via phosphatidylinositide interactions. This ring acts as a diffusion barrier to localise proteins involved in polarity and membrane curvature generation, such as BAR proteins, leading to the extension of a rigid penetration hypha able to rupture plant cuticles [56]. Even if the functioning of $A$. brassicicola appressoria must partly differ from that of $M$. oryzae appressoria, it appears possible that mutations of MCC/ eisosome components altered the A. brassicicola capacity to focus the force at a single point for tissue invasion. In C. albicans, $\Delta s u r 7$ and $\Delta n c e 102$ mutants also exhibited a defect to form invasive hyphae, which is partly due to a partial defect in actin organization and mislocalization of septins and actin [58], and showed a greatly reduced virulence in a mouse model of systemic infection [30,31].

$\mathrm{MCC} /$ eisosome components were also linked to some signaling kinases that were shown to be involved in appressorium formation and pathogenicity in several plant pathogens. For instance, connections between eisosomes and the mitogen-activated protein kinase (MAPK) pathways mediated by Slt2/Mps1 and Fus3/Pmk1 were reported [20, 23, 27]. In A. brassicicola, [59] showed that the AbSLT2-mediated cell wall integrity pathway was essential for full expression of fungal virulence. The $\Delta a b s l t 2$ mutant produced less appressoria than the reference strain and consequently was impaired in its tissue penetration capacity [59]. The Pmk1 MAPK pathway was also shown to be essential for appressorium formation and invasive growth in $M$. oryzae [60] and in other plant pathogenic fungi that do not use physical force to break the plant cuticle, such as Claviceps purpurea, Mycosphaerella graminicola, and Stagonospora nodorum [61]. In A. brassicicola, the Pmk1 homolog (Amk1) was also essential for full virulence and the amk1 mutant produced a majority of swollen and immature appresorium-like structures [62]. Moreover, an increasing body of evidence suggests the existence of crosstalk in $M$. oryzae between the Pmk1 MAPK pathway and autophagy, which is also an essential pathway for appressorium formation [63]. According to these results, we can speculate that the defect of appressorium formation in $\mathrm{MCC} /$ eisosome mutant domains was caused, at least in part, by actin/septin mislocalisation and/or alteration of the autophagic process and/or improper regulation of MAPK cascades in these specialised infection structures. Next steps of this work will be to validate the potential involvement of these molecular factors in the appressorium formation.

\section{Conclusions}

In this study we identified several potential MCC/eisosomal protein encoding genes in the plant pathogenic fungus $A$. brassicicola. As expected, the PM is the primary localization of these proteins in the A. brassicicola cells. As previously shown in other fungi, the deletion of pill and/ or $l s p 1$ homologs altered the conidial cell wall phenotype as well as the aspect of autophagosomes. While the growth of deficient strains was not or only slightly affected by exposure to various stresses, we found that most of the MCC/eisosomal mutants had reduced virulence on B. oleracea leaves and were impaired in their capacity to efficiently colonize $A$. thaliana seeds. Since these mutants exhibited a very low appressorium formation rate, we hypothesized that their defect in aggressiveness was caused, at least in part, by a reduced capacity to gain entry to plant internal tissues. This study suggests that interfering with integrity and functions of potential $\mathrm{MCC} /$ eisosome domains would be an effective plant disease control strategy. 


\section{Methods}

\section{Strains and culture conditions}

The A. brassicicola wild-type strain Abra43 used in this study was previously described [64]. For routine culture, A. brassicicola was grown and maintained on potato dextrose agar (PDA).

Concerning the phenotyping of wild-type and mutant strains, the sorbitol assays were carried out on PDA plates at $24{ }^{\circ} \mathrm{C}$ supplemented or not with $2 \mathrm{M}$ sorbitol and incubated for 10 days. In all cases, colony diameters were measured and used for calculation of radial growth. All the other assays were carried out in liquid media. Conidial suspensions $\left(10^{5}\right.$ conidia/mL, final concentration) were inoculated onto microplate wells containing the considered substance at the desired concentration in potato dextrose broth (PDB, Difco) in a total volume of $300 \mathrm{Ml}$. medium was thus supplemented with brassinin $(100 \mu \mathrm{M})$, camalexin $(60 \mu \mathrm{M})$, Congo Red $(100 \mathrm{mg} / \mathrm{mL})$, Calcofluor White (400 $\mathrm{mg} / \mathrm{mL}$ ), dimethyl sulfoxide (DMSO, 1\%), and menadione $(30 \mathrm{mM})$, respectively. Brassinin was synthesized according to $[65,66]$ while camalexin was synthesized according to [67]. The solvent use for camalexin and brassinin was DMSO and the concentrations in controls and assays did not exceed $0.5 \%(\mathrm{v} / \mathrm{v})$. Microplates were placed in a laser-based microplate nephelometer (NEPHELOstar, BMG Labtech) and growth was monitored automatically over a $30 \mathrm{~h}$ period. Each condition was tested at least in triplicate and the experiments were repeated three times. Nephelometry, which is based on scattered light measurements, was proved to be an accurate indicator of the fungal biomass and can be used as reliable tool for fungal growth monitoring [68]. Data were exported from Nephelostar Galaxy software and further processed in $\mathrm{R}$ Studio. Under curve area were calculated and analyzed from the growth curves.

For transcriptomic analyses, brassinin $(100 \mu \mathrm{M})$ or camalexin $(50 \mu \mathrm{M})$ were added to 1 -day-old germinating conidia $\left(10^{5}\right.$ conidia. $\mathrm{mL}^{-1}$, final concentration) grown in potato dextrose broth (PDB). Incubation was then carried out for 0.5 and $2 \mathrm{~h}$ at $24{ }^{\circ} \mathrm{C}$. Controls were performed by adding DMSO ( $1 \% \mathrm{v} / \mathrm{v}$ final concentration) instead of the tested compound. Sorbitol and desiccation stresses were achieved either by exposing the fungal cultures to $1.2 \mathrm{M}$ sorbitol for $0.5 \mathrm{~h}$ and $2 \mathrm{~h}$ (osmotic stress) or by applying to the germlings a drastic decrease in relative humidity by exposure to silica gel beads in sealed boxes for $1 \mathrm{~h}$ and $4 \mathrm{~h}$ (dehydration stress), as described by [39]. Conidia were first incubated for $24 \mathrm{~h}$ on cellophane disks overlaid on solid PDA medium. Germlings and the underlying cellophanes were then taken off from the agar plate and transferred either to a second PDA medium supplemented or not with $1.2 \mathrm{M}$ sorbitol, or in sealed boxes with or without silica gel beads.

\section{Generation of targeted gene replacement constructs and} fungal transformation

The gene replacement cassettes were generated using the double-joint PCR procedure [69] as described by [39] and with primers presented in the Additional file 1: Table S1. They contained the $5^{\prime}$ and 3 ' flanking regions of each targeted gene fused with the $\mathrm{Hph}$ gene cassette (1436 bp) from pCB1636 [70] or the Nat gene cassette (2150 bp) from pNR [71] conferring resistance to hygromycin $\mathrm{B}$ and nourseotricin, respectively. Knockout mutants deficient for AbPIL1A, AbSLM1, AbNCE102 (called $\Delta a b p i l 1 a, \Delta a b s l m 1$, and $\triangle a b n c e 102)$, respectively, were constructed by replacing the respective ORFs with a hygromycin B resistance cassette while $\triangle a b p i l 1 b$ strains were generated using a nourseothricin resistance cassette. The $\Delta a b p i l 1 a$ genotype was used to obtain $\Delta$ abpil1a-abpil1b hygromycin B and nourseotricin resistant strains. The double-joint final PCR products were transformed into A. brassicicola protoplasts as described by [72]. For each targeted gene, three replacement mutants were selected using a PCR screen (Additional file 4: Figure S3) and purified by two rounds of single-spore isolation. In all further experiments, the phenotypic characters for the three transformants of the same genotype were not found to be significantly different and the results presented here correspond to means of values obtained for individuals carrying the same mutation.

\section{Generation and examination of fusion protein constructs} The Abpil1a, Abpil1b, AbSur7 and AbNce102 C-terminal GFP fusion constructs were generated by fusion PCR as described by [73]. Using A. brassicicola genomic DNA as a template, the respective ORFs and 3' flanking regions were amplified with relevant primer combinations (Additional file 1: Table S1). In parallel, a fragment containing the GFP cassettes and $H y g B$ cassettes were amplified from the plasmid pCT74 [74]. The resulting PCR fragments were mixed and subjected to second fusion PCR. A linker containing three glycine residues was introduced at the 3'end of the respective ORFs to replace the stop codons. The final PCR products were transformed in the $A$. brassicicola wild-type as described above. The transformants with expected genetic integration events were identified by PCR. Observations were performed under a Nikon (Nikon Instruments, Melville, NY) A1S1 confocal laser microscope equipped with argon-ion $(488 \mathrm{~nm})$ and diode $(561 \mathrm{~nm})$ lasers.

\section{Electron microscopy}

The fungal cell ultrastructure was investigated by TEM (transmission electron microscopy) using conidial suspensions obtained from 7-day-old cultures on PDA. The sample fixation was done by $2 \%$ glutaraldehyde and $2 \%$ perfluoroalkoxy buffered at $\mathrm{pH} 7.4$ with $0.1 \mathrm{M}$ sodium cacodylate at night under vacuum at room temperature. Fungal cells were postfixed for $1 \mathrm{~h}$ in $\mathrm{OsO}_{4} 1 \%$, dehydrated in 
ethanol and embedded in Epon. Thin sections were contrasted with uranyle acetate examined under a JEM-1400 transmission electron microscope (Jeol, Paris, France).

SEM (scanning electron microscopy) pictures were acquired with the Phenom Pro desktop SEM (PhenomWorld). The samples were directly imaged in their natural state without modification or preparation. Appressorium formation data were obtained using logistic (logit) generalized linear models as previously described [37].

\section{Gene expression monitoring}

Total RNA extraction and microarray analysis were performed as described by [39]. The Abra_v1.0 chip (Nimblegen, Madison, WI) contained 10,633 60-mer oligoprobes that were designed from the A. brassicicola genome database (https://genome.jgi.doe.gov/Altbr1/Altbr1.home.html). Three biological replicates were analyzed per comparison using the dye-switch method. Only probes with a $P$-values $\leq 0.05$ and a $\log 2$ ratio $\geq 0.5$ or $\leq-0.5$ were considered as differentially expressed. Gene expression datasets were deposited in the Gene Expression Omnibus (GEO) with the following accession numbers, GE140386 and GSE133507.

\section{Infection assays}

Plant infection assays were performed on Brassica oleracea (var. Bartolo), as previously described [59]. Symptoms were observed at 5 days post-inoculation (dpi). The experiment was repeated 5 times and for each experiment each genotype was inoculated onto 9 leaves.

Silique infection assays and seed contamination assessments were performed as previously reported [37]. A. thaliana Ler seeds were provided by the Nottingham Arabidopsis Stock Center.

\section{Supplementary information}

Supplementary information accompanies this paper at https://doi.org/10. 1186/s12866-019-1667-4

Additional file 1: Table S1: List of primers used in this study

Additional file 2: Figure S1: Venn diagrams showing global modulation of gene expression in $A$. brassicicola in response to brassinin and camalexin treatments. Phytoalexin treatments were compared to non-treated cultures at two time points $0.5 \mathrm{~h}$ and $2 \mathrm{~h}$. Genes with a $P$ values $\leq 0.05$ and a $\log 2$ ratio $\geq 0.7$ or $\leq-0.7$ were considered as differentially expressed.

Additional file 3: Figure S2: Representative growth of wild-type (WT) and respective MCC/eisosome mutants. a Radial growth in standard solid medium (PDA) after incubation at $22^{\circ} \mathrm{C}$ for 5 days. b Growth curves monitored in a laser-based microplate nephelometer over a $30 \mathrm{~h}$ period in standard liquid medium (PDB)

Additional file 4: Figure S3: Generation of $\triangle a b p i l 1 a, \Delta a b p i l 1 b, \Delta a b s / m 1$, and $\Delta a b n c e 102$ by homologous recombination. a Schematic representation of a targeted locus in WT and in mutant strains after integration of the replacement construct containing the hygromycin B (Hph gene) or the nourseothricin (Nat gene) resistance cassette and flanking sequences. Primers used for PCR screening of mutants are indicated. $\mathbf{b}$ Gel electrophoresis of PCR products obtained from template

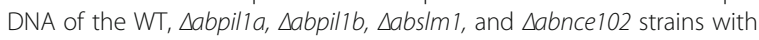

the indicated primer pairs. Molecular sizes (kb) were estimated based on a $1 \mathrm{~kb}$ ladder (lane L2, New England Biolabs) or SmartLadder (Lane L1, Eurogentec). ITS1/4 primers were used as a positive control for PCR.

\section{Abbreviations}

AH domain: Arfaptin homology domain; BAR domain: Bin/Amphiphysin/Rvs domain; DMSO: dimethyl sulfoxide; dpi: days post-infection; ER: Endoplasmic reticulum; GFP: Green fluorescent protein; JGI: Joint genome institute; MAPK: Mitogen-activated protein kinase; MCC: Membrane compartment of Can1; MCP: Membrane compartment Pma1; MCT: Membrane compartment of TORC2; MCW: Membrane compartment occupied by WsC1; ORF: Open reading frame; PCR: Polymerase chain reaction; PDA: Potato dextrose agar; PDB: Potato dextrose broth; PI4,5P 2 : Phosphatidylinositol 4,5- bisphosphate; PM: Plasma membrane; SEM: Scanning electron microscopy;

TEM: Transmission electron microscopy; TOR: The target of rapamycin; WT: Wild-type

\section{Acknowledgments}

We are grateful to members of the IMORPHEN facility for providing plants and we thank the IMAC facility and the SCIAM platform for assistance during microscopic observations.

\section{Authors'contribution}

$\mathrm{JC}$ was the main person involved in the construction and phenotyping of $A$. brassicicola mutant strains and she received help from OD, KF and AK. GN carried out sample preparation and microarray analyses. FB, SA and BH were involved in pathological tests. PS and TG conceived the study, participated in the design of the experiments as well as in the analysis of the results. TEM samples were prepared and examined by FM. All authors read and approved the final manuscript

\section{Funding}

This research, in particular the PhD project associated to this study, was supported by grants awarded by the Region des Pays de la Loire in the framework « RFI Objectif végétal. The funding bodies did not have any role in the design of the study, collection, analysis, and interpretation of data, and in writing the manuscript.

Availability of data and materials

Gene expression datasets were deposited in the Gene Expression Omnibus (GEO) (https://www.ncbi.nlm.nih.gov/geo/query/acc.cgi?acc=GSE133507 and https://www.ncbi.nlm.nih.gov/geo/query/acc.cgi?acc=GSE140386). The biological material used and analyzed during the current study is available from the corresponding author on reasonable request.

Ethics approval and consent to participate

Not applicable.

Consent for publication

Not applicable.

Competing interests

The authors declare that they have no competing interests.

\section{Author details}

${ }^{1}$ Institut de Recherche en Horticulture et Semences - UMR 1345, INRA, Université d'Angers, Agrocampus-Ouest, SFR 4207 QuaSaV, 42 rue Georges Morel, 49071 Beaucouzé Cedex, Angers, France. ${ }^{2}$ Institut de Biologie Intégrative et des Systèmes, Département de Biologie, PROTEO, Université Laval, Pavillon Charles-Eugène-Marchand, 1030 Avenue de la Médecine, QC, Québec G1V 0A6, Canada. ${ }^{3}$ ANSES, Laboratoire de la Santé des Végétaux, Unité de Mycologie, Domaine de Pixérécourt, 54220 Malzéville, France. ${ }^{4}$ Plateforme SCIAM, Institut de Biologie en Santé, CHU, Université d'Angers, 4, Rue Larrey, 49933 Angers Cedex, France. 
Received: 24 September 2019 Accepted: 28 November 2019 Published online: 16 December 2019

\section{References}

1. Van Der Rest M, Kamminga AH, Nakano A, Anraku Y, Poolman B, Konings WN. The plasma membrane of Saccharomyces cerevisiae: structure, function, and biogenesis. Microbiol Rev. 1995;59.

2. Foderaro J, Douglas L, Konopka J. MCC/Eisosomes regulate Cell Wall synthesis and stress responses in Fungi. J Fungi. 2017:3:61.

3. Malinsky J, Opekarová M, Grossmann G, Tanner W. Membrane microdomains, rafts, and detergent-resistant membranes in plants and Fungi. Annu Rev Plant Biol. 2013;64:501-29.

4. Young ME, Karpova TS, Brugger B, Moschenross DM, Wang GK, Schneiter R, et al. The Sur7p family defines novel cortical domains in Saccharomyces cerevisiae, affects Sphingolipid metabolism, and is involved in sporulation. Mol Cell Biol. 2002;22:927-34.

5. Malinska K. Distribution of Can1p into stable domains reflects lateral protein segregation within the plasma membrane of living S. cerevisiae cells. J Cel Sci. 2004;117:6031-41.

6. Malínská K, Malínskỳ J, Opekarová M, Tanner W. Visualization of protein compartmentation within the plasma membrane of living yeast cells. Mol Biol Cell. 2003;14:4427-36.

7. Berchtold D, Walther TC. TORC2 plasma membrane localization is essential for cell viability and restricted to a distinct domain. MBoC. 2009;20:1565-75.

8. Kock C, Arlt H, Ungermann C, Heinisch JJ. Yeast cell wall integrity sensors form specific plasma membrane microdomains important for signalling: microcompartments with yeast CWI sensors. Cell Microbiol. 2016;18:1251-67.

9. Lee J-H, Heuser JE, Roth R, Goodenough U. Eisosome ultrastructure and evolution in Fungi, microalgae, and lichens. Eukaryot Cell. 2015;14:1017-42.

10. Walther TC, Brickner JH, Aguilar PS, Bernales S, Pantoja C, Walter P. Eisosomes mark static sites of endocytosis. Nature. 2006;439:998-1003.

11. Stradalova V, Stahlschmidt W, Grossmann G, Blazikova M, Rachel R, Tanner W, et al. Furrow-like invaginations of the yeast plasma membrane correspond to membrane compartment of Can1. J Cell Sci. 2009;122:2887-94.

12. Malinsky J, Opekarová M, Tanner W. The lateral compartmentation of the yeast plasma membrane. Yeast. 2010;27:473-8

13. Brach T, Specht T, Kaksonen M. Reassessment of the role of plasma membrane domains in the regulation of vesicular traffic in yeast. J Cell Sci. 2011;124:328-37.

14. Grossmann G, Opekarová M, Malinsky J, Weig-Meckl I, Tanner W. Membrane potential governs lateral segregation of plasma membrane proteins and lipids in yeast. EMBO J. 2007;26:1-8.

15. Alvarez FJ, Douglas LM, Rosebrock A, Konopka JB. The Sur7 protein regulates plasma membrane organization and prevents intracellular Cell Wall growth in Candida albicans. MBoC. 2008;19:5214-25.

16. Fröhlich F, Moreira K, Aguilar PS, Hubner NC, Mann M, Walter P, et al. A genome-wide screen for genes affecting eisosomes reveals Nce102 function in sphingolipid signaling. J Cell Biol. 2009;185:1227-42.

17. Karotki L, Huiskonen JT, Stefan CJ, Ziółkowska NE, Roth R, Surma MA, et al. Eisosome proteins assemble into a membrane scaffold. J Cell Biol. 2011;195: 889-902.

18. Douglas LM, Konopka JB. Fungal membrane organization: the Eisosome concept. Annu Rev Microbiol. 2014;68:377-93.

19. Walther TC, Aguilar PS, Fröhlich F, Chu F, Moreira K, Burlingame AL, et al. Pkh-kinases control eisosome assembly and organization. EMBO J. 2007;26: 4946-55.

20. Zhang X, Lester RL, Dickson RC. Pil1p and Lsp1p negatively regulate the 3 Phosphoinositide-dependent protein kinase-like kinase Pkh1p and downstream signaling pathways Pkc1p and Ypk1p. J Biol Chem. 2004;279:22030-8.

21. Deng C, Xiong X, Krutchinsky AN. Unifying fluorescence microscopy and mass spectrometry for studying protein complexes in cells. Mol Cell Proteomics. 2009:8:1413-23.

22. Luo G, Gruhler A, Liu Y, Jensen ON, Dickson RC. The Sphingolipid Long Chain Base-Pkh1/2-Ypk1/2 signaling pathway regulates Eisosome assembly and turnover. J Biol Chem. 2008:283:10433-44.

23. Mascaraque V, Hernáez ML, Jiménez-Sánchez M, Hansen R, Gil C, Martín H, et al. Phosphoproteomic analysis of protein kinase $\mathrm{C}$ signaling in Saccharomyces cerevisiae reveals Slt2 mitogen-activated protein kinase (MAPK)-dependent phosphorylation of Eisosome Core components. Mol Cell Proteomics. 2013;12:557-74.
24. Fröhlich F, Christiano R, Olson DK, Alcazar-Roman A, DeCamilli P, Walther TC. A role for eisosomes in maintenance of plasma membrane phosphoinositide levels. Mol Biol Cell. 2014;25:2797-806.

25. Kabeche R, Roguev A, Krogan NJ, Moseley JB. A Pil1-Sle1-Syj1-Tax4 functional pathway links eisosomes with PI(4,5)P2 regulation. J Cell Sci. 2014;127:1318-26.

26. Buser C, Drubin DG. Ultrastructural imaging of Endocytic sites in Saccharomyces cerevisiae by transmission Electron microscopy and Immunolabeling. Microsc Microanal. 2013;19:381-92.

27. Kabeche R, Howard L, Moseley JB. Eisosomes provide membrane reservoirs for rapid expansion of the yeast plasma membrane. J Cell Sci. 2015;128:4057-62.

28. Dupont S, Beney L, Ritt J-F, Lherminier J, Gervais P. Lateral reorganization of plasma membrane is involved in the yeast resistance to severe dehydration. Biochim et Biophys Acta (BBA) - Biomembr. 2010;1798:975-85.

29. Zhang L-B, Tang L, Ying S-H, Feng M-G. Two eisosome proteins play opposite roles in autophagic control and sustain cell integrity, function and pathogenicity in Beauveria bassiana: two eisosome proteins vital for $B$. bassiana. Environ Microbiol. 2017:19:2037-52.

30. Douglas LM, Wang HX, Konopka JB. The MARVEL Domain Protein Nce102 Regulates Actin Organization and Invasive Growth of Candida albicans. mBio. 2013;4. doi:https://doi.org/10.1128/mBio.00723-13.

31. Douglas LM, Wang HX, Keppler-Ross S, Dean N, Konopka JB. Sur7 Promotes Plasma Membrane Organization and Is Needed for Resistance to Stressful Conditions and to the Invasive Growth and Virulence of Candida albicans. mBio. 2011;3. https://doi.org/10.1128/mBio.00254-11.

32. Hopke A, Nicke N, Hidu EE, Degani G, Popolo L, Wheeler RT. Neutrophil attack triggers extracellular trap-dependent Candida Cell Wall remodeling and altered immune recognition. PLoS Pathog. 2016;12:e1005644.

33. Bernardo SM, Lee SA. Candida Research article albicans SUR7 contributes to secretion, biofilm formation, and macrophage killing. 2010;:15.

34. Atanasova L, Gruber S, Lichius A, Radebner T, Abendstein L, Münsterkötter M, et al. The Gpr1-regulated Sur7 family protein Sfp2 is required for hyphal growth and cell wall stability in the mycoparasite Trichoderma atroviride. Sci Rep. 2018;8:12064.

35. Van den Bosch F, Fraaije BA, van den Berg F, Shaw MW. Evolutionary bistability in pathogen transmission mode. Proc Royal Soc B. 2010;277. https:// doi.org/10.1098/rspb.2009.2211.

36. Vangelatos I, Roumelioti K, Gournas C, Suarez T, Scazzocchio C, Sophianopoulou V. Eisosome Organization in the Filamentous AscomyceteAspergillus nidulans. Eukaryot Cell. 2010;9:1441-54.

37. Pochon S, Terrasson E, Guillemette T, lacomi-Vasilescu B, Georgeault S, Juchaux M, et al. The Arabidopsis thaliana-Alternaria brassicicola pathosystem: a model interaction for investigating seed transmission of necrotrophic fungi. Plant Methods. 2012;8:16.

38. Pochon S, Simoneau P, Pigné S, Balidas S, Bataillé-Simoneau N, Campion C, et al. Dehydrin-like proteins in the Necrotrophic fungus Alternaria brassicicola have a role in plant pathogenesis and stress response. PLoS One. 2013;8:e75143.

39. N'Guyen GQ, Raulo R, Marchi M, Agustí-Brisach C, lacomi B, Pelletier S, et al. Responses to hydric stress in the seed-borne Necrotrophic fungus Alternaria brassicicola. Front Microbiol. 2019:10:1969.

40. Talbot NJ. Appressoria. Curr Biol. 2019;29:R144-6.

41. Seger S, Rischatsch R, Philippsen P. Formation and stability of eisosomes in the filamentous fungus Ashbya gossypii. J Cell Sci. 2011;124:1629-34.

42. Reijnst $P$, Walther A, Wendland J. Dual-colour fluorescence microscopy using yEmCherry-/GFP-tagging of eisosome components Pil1 and Lsp1 in Candida albicans. Yeast. 2011:28:331-8.

43. Athanasopoulos A, Gournas C, Amillis S, Sophianopoulou V. Characterization of AnNce102 and its role in eisosome stability and sphingolipid biosynthesis. Sci Rep. 2015;5:15200.

44. Wang HX, Douglas LM, Veselá P, Rachel R, Malinsky J, Konopka JB. Eisosomes promote the ability of Sur7 to regulate plasma membrane organization in Candida albicans. Mol Biol Cell. 2016;27:1663-75.

45. Singer-Krüger B, Nemoto Y, Daniell L, Ferro-Novick S, Camilli PD. Synaptojanin family members are implicated in endocytic membrane traffic in yeast. Journal of Cell Science. 1998;111:3347-56.

46. Badrane H, Nguyen MH, Blankenship JR, Cheng S, Hao B, Mitchell AP, et al. Rapid redistribution of phosphatidylinositol-(4,5)-Bisphosphate and Septins during the Candida albicans response to Caspofungin. Antimicrob Agents Chemother. 2012:56:4614-24

47. Hu G, McQuiston T, Bernard A, Park Y-D, Qiu J, Vural A, et al. A conserved mechanism of TOR-dependent RCK-mediated mRNA degradation regulates autophagy. Nat Cell Biol. 2015;17:930-42. 
48. Yorimitsu T, Klionsky DJ. Autophagy: molecular machinery for self-eating. Cell Death Differ. 2005;12:1542-52.

49. Xie Z, Klionsky DJ. Autophagosome formation: core machinery and adaptations. Nat Cell Biol. 2007;9:1102-9.

50. Cho Y. How the Necrotrophic fungus Alternaria brassicicola kills plant cells remains an enigma. Eukaryot Cell. 2015:14:335-44.

51. Tucker SL, Talbot NJ. Surface attachment and pre-penetration stage development by plant pathogenic fungi. Annu Rev Phytopathol. 2001;39: 385-417.

52. de Jong JC, McCormack BJ, Smirnoff N, Talbot NJ. Glycerol generates turgor in rice blast. Nature. 1997;389.

53. Yan X, Talbot NJ. Investigating the cell biology of plant infection by the rice blast fungus Magnaporthe oryzae. Curr Opin Microbiol. 2016;34:147-53.

54. Khan A, McQuilken M, Gladfelter AS. Septins and generation of asymmetries in fungal cells. Annu Rev Microbiol. 2015;69:487-503.

55. Bridges AA, Gladfelter AS. Septin form and function at the cell cortex. J Biol Chem. 2015;290:17173-80.

56. Dagdas YF, Yoshino K, Dagdas G, Ryder LS, Bielska E, Steinberg G, et al. Septin-Mediated Plant Cell Invasion by the Rice Blast Fungus. 2012;336:7

57. Momany M, Talbot NJ. Septins focus cellular growth for host infection by pathogenic Fungi. Frontiers in Cell and Developmental Biology. 2017;5. https://doi.org/10.3389/fcell.2017.00033.

58. Alvarez FJ, Douglas LM, Konopka JB. The Sur7 protein resides in punctate membrane subdomains and mediates spatial regulation of cell wall synthesis in Candida albicans. Communicative Integr Biol. 2009;2: 76-7.

59. Joubert A, Bataille-Simoneau N, Campion C, Guillemette T, Hudhomme P, lacomi-Vasilescu B, et al. Cell wall integrity and high osmolarity glycerol pathways are required for adaptation of Alternaria brassicicola to cell wall stress caused by brassicaceous indolic phytoalexins: Camalexin activation of HOG and CWI pathways. Cell Microbiol. 2011;13:62-80.

60. Bruno KS, Tenjo F, Li L, Hamer JE, XU J-R. Cellular localization and role of kinase activity of PMK1 in Magnaporthe grisea. Eukaryot Cell. 2004;3: 1525-32.

61. Turrà D, Segorbe D, Di Pietro A. Protein kinases in plant-pathogenic Fungi: conserved regulators of infection. Annu Rev Phytopathol. 2014; 52:267-88.

62. Cho Y, Cramer RA Jr, Kim K-H, Davis J, Mitchell TK, Figuli P, et al. The Fus3/ Kss1 MAP kinase homolog Amk1 regulates the expression of genes encoding hydrolytic enzymes in Alternaria brassicicolart. Fungal Genet Biol. 2007:44:543-53.

63. Zhu X-M, Liang S, Shi H-B, Lu J-P, Dong B, Liao Q-S, et al. VPS9 domaincontaining proteins are essential for autophagy and endocytosis in Pyricularia oryzae: VPS9 domain-containing proteins in P. oryzae. Environ Microbiol. 2018:20:1516-30.

64. Sellam A, lacomi-Vasilescu B, Hudhomme P, Simoneau P. In vitro antifungal activity of brassinin, camalexin and two isothiocyanates against the crucifer pathogens Alternaria brassicicola and Alternaria brassicae. Plant Pathol. 2007;56. https://doi.org/10.1111/j.1365-3059.2006.01497.x.

65. Kutschy P, Dzurilla M, Takasugi M, Török M, Achbergerová I, Homzová R, et al. New syntheses of indole phytoalexins and related compounds. Tetrahedron. 1998;54:3549-66.

66. Takasugi M, Monde K, Katsui N, Shirata A. Novel sulfur-containing phytoalexins from the chinese cabbage Brassica campestris L. ssp. pekinensis (Cruciferae). Bull. Chem. Soc. Jpn. 1988;61:285-89.

67. Ayer WA, Craw PA, Ma Y, Miao S. Synthesis of camalexin and related phytoalexins. Tetrahedron. 1992;48:2919-24.

68. Joubert A, Calmes B, Berruyer R, Pihet M, Bouchara J-P, Simoneau P, et al. Laser nephelometry applied in an automated microplate system to study filamentous fungus growth. BioTechniques. 2010;48:399-404.

69. Yu J-H, Hamari Z, Han K-H, Seo J-A, Reyes-Domínguez Y, Scazzocchio C. Double-joint PCR: a PCR-based molecular tool for gene manipulations in filamentous fungi. Fungal Genet Biol. 2004;41:973-81.

70. Sweigard JA, Chumley F, Carroll A, Farrall L, Valent B. A series of vectors for fungal transformation. Fungal Genet Rep. 1997;44:52-3.

71. Malonek S, Rojas MC, Hedden P, Gaskin P, Hopkins P, Tudzynski B. The NADPH-cytochrome P450 Reductase gene from Gibberella fujikuroi is essential for gibberellin biosynthesis. J Biol Chem. 2004;279:25075-84.

72. Cho Y, Davis JW, Kim K-H, Wang J, Sun Q-H, Cramer RA, et al. A high throughput targeted gene disruption method for Alternaria brassicicola functional genomics using linear minimal element (LME) constructs. Mol Plant-Microbe Interact. 2006;19:7-15.

73. Calmes B, Guillemette T, Teyssier L, Siegler B, Pigné S, Landreau A, et al. Role of mannitol metabolism in the pathogenicity of the necrotrophic fungus Alternaria brassicicola. Front Plant Sci. 2013;4. https://doi.org/10.3389/fpls. 2013.00131.

74. Lorang JM, Tuori RP, Martinez JP, Sawyer TL, Redman RS, Rollins JA, et al. Green fluorescent protein is lighting up fungal biology. Appl Environ Microbiol. 2001:67:1987-94.

\section{Publisher's Note}

Springer Nature remains neutral with regard to jurisdictional claims in published maps and institutional affiliations.

\section{Ready to submit your research? Choose BMC and benefit from:}

- fast, convenient online submission

- thorough peer review by experienced researchers in your field

- rapid publication on acceptance

- support for research data, including large and complex data types

- gold Open Access which fosters wider collaboration and increased citations

- maximum visibility for your research: over $100 \mathrm{M}$ website views per year

At BMC, research is always in progress.

Learn more biomedcentral.com/submissions 